\title{
The prevalence of chronic ankle instability in basketball athletes: a cross-sectional study
}

Chiao-I Lin ${ }^{1,2^{*}}$, Frank Mayer ${ }^{2,3}$ and Pia-Maria Wippert ${ }^{1,2}$

\begin{abstract}
Background: Ankle sprain is the most common injury in basketball. Chronic ankle instability develops from an acute ankle sprain may cause negative effects on quality of life, ankle functionality or on increasing risk for recurrent ankle sprains and post-traumatic osteoarthritis. To facilitate a preventative strategy of chronic ankle instability (CAI) in the basketball population, gathering epidemiological data is essential. However, the epidemiological data of CAl in basketball is limited. Therefore, this study aims to investigate the prevalence of CAI in basketball athletes and to determine whether gender, competitive level, and basketball playing position influence this prevalence.

Methods: In a cross-sectional study, in total 391 Taiwanese basketball athletes from universities and sports clubs participated. Besides non-standardized questions about demographics and their history of ankle sprains, participants further filled out the standard Cumberland Ankle Instability Tool applied to determine the presence of ankle instability. Questionnaires from 255 collegiate and 133 semi-professional basketball athletes ( male $=243$, female $=145$, $22.3 \pm 3.8$ years, $23.3 \pm 2.2 \mathrm{~kg} / \mathrm{m}^{2}$ ) were analyzed. Differences in prevalence between gender, competitive level and playing position were determined using the Chi-square test.

Results: In the surveyed cohort, $26 \%$ had unilateral CAI while $50 \%$ of them had bilateral CAI. Women had a higher prevalence than men in the whole surveyed cohort $\left(X^{2}(1)=0.515, p=0.003\right)$. This gender disparity also showed from sub-analyses, that the collegiate female athletes had a higher prevalence than collegiate men athletes $\left(X^{2}(1)=0.203\right.$, $p=0.001)$. Prevalence showed no difference between competitive levels $(p>0.05)$ and among playing positions $(p>0.05)$.
\end{abstract}

Conclusions: CAl is highly prevalent in the basketball population. Gender affects the prevalence of CAl. Regardless of the competitive level and playing position the prevalence of CAl is similar. The characteristic of basketball contributes to the high prevalence. Prevention of CAI should be a focus in basketball. When applying the CAl prevention measures, gender should be taken into consideration.

Keywords: Functional ankle instability, Perceived ankle instability, Ankle sprain, Ankle injury, Survey, Basketball

\section{Background}

Ankle sprain is one of the most common injuries among active individuals [1]. Residual symptoms after an acute ankle sprain such as pain, swelling, giving way or

\footnotetext{
*Correspondence: linchiaoi@gmail.com

${ }^{1}$ Medical Sociology and Psychobiology, Department of Physical Activity and Health, University of Potsdam, Am Neuen Palais 10, 14469 Potsdam, Germany

Full list of author information is available at the end of the article
}

weakness are also prevalent [2]. In a follow-up 2.4 years after an acute ankle sprain, $74 \%$ of patients had residual symptoms [2]. The residual symptoms vary among the patients $[3,4]$. The terms of this pathology are also diverse (e.g. chronic ankle instability (CAI), chronic ankle sprain or recurrent lateral ankle instability) $[3,5]$. To standardize CAI for research purposes, the International Ankle Consortium characterized CAI as a pathology occurring among individuals who have a history of significant ankle sprains, experience "giving way," and/ original author(s) and the source, provide a link to the Creative Commons licence, and indicate if changes were made. The images or other third party material in this article are included in the article's Creative Commons licence, unless indicated otherwise in a credit line to the material. If material is not included in the article's Creative Commons licence and your intended use is not permitted by statutory regulation or exceeds the permitted use, you will need to obtain permission directly from the copyright holder. To view a copy of this licence, visit http://creativecommons.org/licenses/by/4.0/. The Creative Commons Public Domain Dedication waiver (http://creativeco mmons.org/publicdomain/zero/1.0/) applies to the data made available in this article, unless otherwise stated in a credit line to the data. 
or recurrent sprain, and/or "feelings of instability in the injured ankle" [3].

Based on the model from Van Mechelen, the first step of sports injuries prevention is to identify the severity and the incidence [6]. The severity of CAI is well documented [4]. CAI induces different short- to long-term negative consequences. For example, declined physical activity in long-term, decreased quality of life, recurring ankle sprain, early degenerative joint tissue changes and can potentially increase the load on the anterior cruciate ligament $[4,7]$. In addition, recurrent ankle sprains induced by CAI cause financial burden and time loss [4]. To manage ankle sprains, direct costs range from 292 to 2268 USD per person and indirect costs are between 1482 and 4343 USD [8]. An ankle sprain results in 21-30 days of lost time for professional football athletes [9]. These negative consequences make the individual prone to further injuries, illness and affect the athletes' time available for practices and games $[4,10]$. To develop an injury prevention strategy for $\mathrm{CAI}$ and its negative consequences, injury surveillance is required [11].

Regarding the incidence of CAI, the epidemiology of ankle sprains is well documented. Yet the prevalence of CAI in basketball is not. Ankle sprain is one of the most common injuries in basketball due to repetitive jumping, cuttings, rapid stops and directional changes [12-14]. Incidences of ankle sprain among professional basketball athletes (National Basketball Association, the Women's National Basketball Association and an elite Spanish basketball club) were between 1.3 and 4.3 per 1000 athlete exposures [15-17]; and among US collegiate athletes were 1.0-2.1 per 1000 athlete exposures [12, 18-20]. Lateral ankle sprain is the most common injury (16.2\%) among US collegiate athletes [13].

Referring to the prevalence of CAI, 19-22\% of all injuries in the basketball athlete population are recurrent ankle sprains $[12,18,21]$. In basketball, $60 \%$ of the participants experienced recurrent ankle sprain, $28 \%$ perceived ankle instability with a history of ankle sprain and $30 \%$ suffered from persistent symptoms after an ankle sprain [22]. In addition, $30 \%$ (17/57) of collegiate basketball athletes in the US and 4-64\% (1/24, 8/22 and 14/22) in Japan had CAI [23-25]. Previous studies showed a wide range of the prevalence of CAI among basketball athletes (4\% to $64 \%)$ and the sample sizes were small $(\mathrm{N}=22-57)$ [2325]. In addition, previous studies excluded athletes with a history of fractures and injuries in the lower extremities even though these athletes may also have CAI so the prevalence of CAI may be underestimated [26]. A survey for basketball athletes should be conducted and athletes with various other ankle issues should also be included to form an accurate picture of the prevalence of CAI.
Gender [15, 18, 21, 27], level of competition [19, 20], and position on court $[18,27]$ have been considered as factors that impact the ankle sprain rate in basketball. Women are considered prone to sports injuries due to physiological differences, e.g. joint laxity and menstrual cycles $[28,29]$. At a higher competitive level, athletes have a higher level of compact body composition [30], intensity [19], athletic exposure [31] and rate of previous ankle sprains [32]. These factors may cause a higher rate of ankle injury compared to the athletes at a lower level [31]. Basketball athletes in different positions do different tasks [33]. Guards with good aerobic and anaerobic capacity perform high-intensive tasks [34]. Forwards run a lot during competition [33]. Centers, the tallest, heaviest and strongest among all basketball positions, carry out rebounding and have a lot of body contact with other opponents during boxouts [34]. The physiological profiles are distinct among play positions [35] and different characteristics may be associated with different injury rates [18]. However, the evidence of injury rate between genders $[15,18,21]$, competitive levels $[19,20]$ and position $[18,27]$ are inconsistent. Once gender, level of competition and played position are correlated with the prevalence of CAI, the second, third and fourth steps of the model from Van Mechelen (establishing underlying mechanisms, developing and evaluating injury prevention programs) can be investigated and specialized $[6$, 36].

Therefore, the purposes of this study were to investigate the prevalence of CAI in elite basketball athletes at different levels (semi-professional and college) and to investigate if the prevalence of CAI is influenced by different genders, competitive levels and positions.

\section{Methods}

\section{Study design and procedure}

This study presents the cross-sectional data of CAI prevalence during the pre-season of the Super Basketball League and the games of the University Basketball Association in Taiwan. The investigator contacted team staff from all semi-professional teams and college teams in Taiwan. Participants filled out a printed questionnaire inquiring demographics, history of ankle sprain/ giving way/recurring ankle sprain and the Taiwan-Chinese version of the Cumberland Ankle Instability Tool Questionnaire (CAIT-TW) after a routine practice [37]. The investigator distributed printed questionnaires and checked the questionnaires when returned it. Study was conducted in October of 2018. All participants read and signed the informed consent document before participating in the study. This study was performed in accordance with the Declaration of Helsinki and was approved by the 
ethical committee at the University of Potsdam (Number: 25/2018).

\section{Participants}

391 elite Taiwanese basketball athletes from 11 semiprofessional and 17 college teams were recruited for this study. 134 athletes (99 men and 35 women) from all the Super Basketball League in Taiwan (semi-professional level) (Additional File 1). 257 athletes (148 men and 109 women) from the University Basketball Association in Taiwan (teams ranked within the top ten in 2017) (Additional File 1). A convenient sampling was applied to select the college teams. Most of the included college teams are from the north of Taiwan. Inclusion criteria were: (1) participants were basketball team members and (2) a minimum age of 18 years. Exclusion criteria were (1) acute injuries in the lower extremities and (2) incomplete questionnaires. Athletes were also excluded if they could not participate in daily practice sessions due to injuries.

\section{Instruments}

There were three sections in the questionnaire: (1) demographics, (2) history of significant ankle sprains/giving way/recurrent ankle sprain, and (3) the CAIT-TW [37].

1. The demographic section included age, gender, height, weight, training hours per week, training experiences, competitive level and playing position.

2. The questions stated:

- Have you sprained your ankle significantly? Which ankle? A significant ankle sprain was associated with inflammatory symptoms, interrupting at least 1 full day of planned physical activity, resulting in some initial deficits of function and disability [3].

- Have you experienced giving way? Giving way refers to regular occurrences of uncontrolled and unpredictable episodes of excessive inversion of the rear foot (usually experienced during initial contact during walking or running), which do not result in an acute lateral ankle sprain and it has happened at least twice in the past six months [3].

- Do you have recurrent ankle sprains? (two or more sprains to the same ankle) [3].

3. The CAIT-TW consisting of nine items was applied to determine the presence of perceived ankle instability [37]. CAIT-TW was culturally adapted from the original English Cumberland Ankle Instability Tool Questionnaire (CAIT) and evaluated the psychometric properties in an athletic population. The CAIT-TW showed excellent test-retest reliability $\left(\mathrm{ICC}_{2.1}=0.91, \mathrm{p}<0.001\right)$, good internal consistency
(Cronbach's $\alpha$ : 0.87), moderate to strong construct validity (CAIT-TW versus Taiwan-Chinese version of Lower Extremity Functional Score: Rho $=0.39$, $\mathrm{p}<0.001$ and strong (CAIT-TW versus Numeric Rating Scale: Rho $=0.76, \mathrm{p}<0.001)$, and a cutoff score of 21.5 (Youden index: 0.73 , sensitivity: 0.87 , specificity 0.85) [37].

\section{Data analysis}

The International Ankle Consortium suggested the inclusion criteria of CAI are individuals who had a history of significant ankle sprain and either (1) experience of giving way twice or more within the past six months, (2) recurrent ankle sprain or (3) perceived ankle instability (the score of CAIT-TW is lower than 22) [3]. To reduce the recall bias on the experience of giving way and recurrent ankle sprain, athletes were considered to have CAI if they have a history of significant ankle sprain(s) and the presence of perceived ankle instability evaluated using CAIT-TW.

All data analysis was performed using IBM SPSS 25.0 (Chicago, Illinois, USA). Descriptive statistics were performed to display the demographic data and prevalence of CAI in the population of basketball athletes (first study purpose). Differences in demographics between participants with CAI and without CAI were examined applying the Mann-Whitney $U$ test or independent T-test depending on the distribution of the data. The Chisquare test was applied to determine the difference in the presence of CAI between genders, two competitive levels and positions on court (second study purpose). The level of significance was set at $\mathrm{p}$-value $\leq 0.05$.

\section{Results}

391 basketball athletes filled out the questionnaire in total, whereby three questionnaires were incomplete. Finally, 388 valid questionnaires were available for analysis $($ men $=243$, women $=145$, college $=255$, semiprofessional $=133$ ). Participants' demographics and the score of CAIT-TW are shown in Additional File 1 $(22.3 \pm 3.8$ years, $179.9 \pm 10.9 \mathrm{~cm}, 76.1 \pm 13.7 \mathrm{~kg})$. In the surveyed cohort, $97 \%$ of the participants experienced ankle sprain, $26 \%$ of them had unilateral CAI while $50 \%$ had bilateral CAI and $24 \%$ of them were without CAI (Additional File 1). There were no demographical differences between participants with CAI and without CAI (Table 1). The demographic data was separated by genders at different competitive levels and presented in Additional files 2, 3, 4.

Gender influenced the presence of CAI (Table 2). Women had a higher prevalence of CAI than men $\left(\mathrm{X}(1)^{2}=0.151, \mathrm{p}=0.003\right)$. When data was separated 
into two levels women had a higher prevalence of CAI than men at the college level $\left(\mathrm{X}(1)^{2}=0.203, \mathrm{p}=0.001\right)$. No difference based on gender has been found at the semi-professional level $\left(\mathrm{X}(1)^{2}=0.203, \mathrm{p}=0.47\right)$ (Table 2).

The competitive level did not influence the presence of CAI $\left(X^{2}=0.054, \mathrm{p}=0.29\right)$ (Table 3$)$. When the data was separated into men and women, there was no difference of prevalence between different competitive levels among both genders (men: $\mathrm{X}^{2}(1)=0.117, \mathrm{p}=0.07$, women: $\left.X^{2}=0.017, \mathrm{p}=0.84\right)$.
For the three positions, the prevalence of CAI consisted of $76 \%$ for guard (124/164), $80 \%$ for forward (118/148), and $74 \%$ for center $(51 / 69)$. The prevalence of CAI did not differ among positions $\left(\mathrm{x}^{2}(2)=0.55, \mathrm{p}=0.56\right)$ (Table 4$)$.

\section{Discussion}

The purpose of this study was (1) to investigate the prevalence of CAI in basketball athletes and (2) to assess if genders, competitive levels or positions influence this prevalence. The prevalence of CAI was high in the studied cohort. Gender affected the prevalence of CAI.

Table 1 Demographical differences between participants with and without chronic ankle instability

\begin{tabular}{|c|c|c|c|}
\hline & $\begin{array}{l}\text { CAI }(n=297) \\
M \pm S D\end{array}$ & $\begin{array}{l}\text { Without CAI }(n=91) \\
M \pm S D\end{array}$ & $\begin{array}{l}\text { Difference } \\
\text { between } \\
\text { groups }\end{array}$ \\
\hline Age (year) & $22.4 \pm 3.8$ & $21.9 \pm 3.8$ & $p=0.31$ \\
\hline Height (cm) & $179.5 \pm 11.1$ & $181.5 \pm 10.3$ & $p=0.37$ \\
\hline Weight (kg) & $75.7 \pm 13.6$ & $77.5 \pm 13.9$ & $p=0.23$ \\
\hline $\mathrm{BMI}\left(\mathrm{kg} / \mathrm{m}^{2}\right)$ & $23.3 \pm 2.11$ & $23.4 \pm 2.5$ & $p=0.11$ \\
\hline Training hours (h/week) & $18.5 \pm 6.6$ & $18.9 \pm 6.3$ & $p=0.27$ \\
\hline Training experience (year) & $9.3 \pm 3.8$ & $8.8 \pm 3.9$ & $p=0.28$ \\
\hline \multicolumn{4}{|l|}{ CAlT score } \\
\hline Left ankle & $16.4 \pm 5.5$ & $24.8 \pm 2.8$ & $p<0.001^{*}$ \\
\hline Right ankle & $16.7 \pm 5.8$ & $25.1 \pm 3.3$ & $\mathrm{p}<0.001^{*}$ \\
\hline CAl ankle & $15.4 \pm 4.8\left(513^{\#}\right)$ & - & - \\
\hline Non-CAl ankle & $23.8 \pm 5.4\left(81^{\#}\right)$ & $25.5 \pm 3.6$ & $\left(96^{\#}\right)$ \\
\hline
\end{tabular}

$C A /$ chronic ankle instability, $M$ mean, $S D$ standard deviation, $B M I$ body mass index

* A significant difference between groups. "Meaning the number of ankles

Table 2 The prevalence of chronic ankle instability between genders ( $\mathrm{n}, \%)$

\begin{tabular}{|c|c|c|c|c|c|}
\hline & \multicolumn{2}{|c|}{ Men $(n=243)$} & \multicolumn{2}{|c|}{ Women $(n=145)$} & \multirow[t]{2}{*}{ Differences between gender } \\
\hline & CAI & Without CAI & CAI & Without CAI & \\
\hline All participants $(\mathrm{N}=388)$ & $174(72 \%)$ & $69(28 \%)$ & $123(85 \%)$ & $22(15 \%)$ & $X^{2}(1)=0.151, p=0.003^{*}$ \\
\hline College $(n=255)$ & $99(67 \%)$ & $48(32 \%)$ & $92(85 \%)$ & $16(15 \%)$ & $X^{2}(1)=0.203, p=0.001^{*}$ \\
\hline Semi-professional $(n=133)$ & 75(78\%) & $21(22 \%)$ & $31(84 \%)$ & $6(16 \%)$ & $X^{2}(1)=0.203, p=0.47$ \\
\hline
\end{tabular}

CAl chronic ankle instability

${ }^{*} \mathrm{p}<0.05$

Table 3 The prevalence of chronic ankle instability between different competitive levels (n, \%)

\begin{tabular}{|c|c|c|c|c|c|}
\hline & \multicolumn{2}{|c|}{ College $(n=255)$} & \multicolumn{2}{|c|}{ Semi-Professional $(n=133)$} & \multirow{2}{*}{$\begin{array}{l}\text { Differences } \\
\text { between } \\
\text { competitive level }\end{array}$} \\
\hline & CAI & Without CAI & CAI & Without CAI & \\
\hline All participants $(\mathrm{N}=388)$ & $191(75 \%)$ & $64(25 \%)$ & $106(80 \%)$ & $27(20 \%)$ & $X^{2}(1)=0.054, p=0.29$ \\
\hline men $(n=243)$ & $99(67 \%)$ & $48(33 \%)$ & 75 (78\%) & $21(22 \%)$ & $X^{2}(1)=0.117, p=0.07$ \\
\hline women $(n=145)$ & $92(85 \%)$ & $16(15 \%)$ & $31(84 \%)$ & $6(16 \%)$ & $X^{2}(1)=0.017, p=0.84$ \\
\hline
\end{tabular}

CAl chronic ankle instability 
Table 4 The prevalence of chronic ankle instability in different playing positions (n, \%)

\begin{tabular}{|c|c|c|c|c|c|c|c|}
\hline & \multicolumn{2}{|c|}{ Guard $(n=164)$} & \multicolumn{2}{|c|}{ Forward $(n=148)$} & \multicolumn{2}{|c|}{ Center $(n=69)$} & \\
\hline & CAI & Without CAI & CAI & Without CAI & CAI & Without CAI & \\
\hline All $(\mathrm{N}=381)$ & $124(76 \%)$ & $40(24 \%)$ & $118(80 \%)$ & $30(20 \%)$ & $51(74 \%)$ & $18(26 \%)$ & $x^{2}(2)=0.55, p=0.56$ \\
\hline College $(n=248)$ & $81(74 \%)$ & $29(26 \%)$ & $69(77 \%)$ & $21(23 \%)$ & $37(77 \%)$ & $11(23 \%)$ & $x^{2}(2)=0.04, p=0.85$ \\
\hline Semi-professional $(n=266)$ & $43(80 \%)$ & $97(20 \%)$ & 49 (85\%) & $9(15 \%)$ & $14(67 \%)$ & $7(33 \%)$ & $x^{2}(2)=0.15, p=0.22$ \\
\hline Men $(n=238)$ & $71(70 \%)$ & $31(30 \%)$ & $80(78 \%)$ & $23(22 \%)$ & $21(64 \%)$ & $12(36 \%)$ & $x^{2}(2)=0.21, p=0.11$ \\
\hline Women $(n=143)$ & $53(86 \%)$ & $115(16 \%)$ & $38(84 \%)$ & $7(16 \%)$ & $30(83 \%)$ & $6(17 \%)$ & $x^{2}(2)=0.02, p=0.96$ \\
\hline
\end{tabular}

CAl chronic ankle instability

Women showed a higher presence of CAI than men. The competitive level and position showed no influence on the prevalence of CAI.

\section{The prevalence of CAI}

Regarding the first objective, the prevalence of CAI in this study cohort was high and above the prevalence of previous studies [23-25, 38]. Female basketball athletes in the current study presented an $85 \%(123 / 145)$ prevalence of CAI. Yet the previous studies showed $4 \%(2 / 26)$ among Japanese collegiate basketball athletes and 64\% among female Australian netball athletes (61/96) [24, 38]. The movement patterns of netball are similar to basketball [38]. Collegiate basketball athletes in the current study displayed a $75 \%(191 / 255)$ prevalence of CAI but previous investigations showed 30\% (17/57) among the US High school and collegiate basketball athletes; and $64 \%(14 / 22)$ and $36 \%(8 / 22)$ in Japanese collegiate basketball athletes [23, 25]. Different exclusion criteria applied in the current and previous studies cause discrepancies in results. The previous studies applied the exclusion criteria suggested by the International Ankle Consortium [3]. These criteria exclude participants with a history of previous surgeries, fractures or acute injuries in the lower extremities [25]. However, the current study included the participants who met the exclusion criteria.

There is a limitation when surveying the prevalence of CAI using the exclusion criteria defined by the International Ankle Consortium. If the participants with CAI are excluded because they have the issues mentioned above, the prevalence of CAI could be underestimated [23-25, 38]. On the other hand, if the participants without CAI have any conditions mentioned in the exclusion criteria, they may also perceive ankle instability. The perceived ankle instability might be owed to the other conditions instead of CAI. In this case, the prevalence of CAI would be overestimated. Therefore, the prevalence in the current study might be overestimated.

The rate of prevalence is almost twice as high when applying the exclusion criteria when investigating the prevalence of CAI [23]. Koshino et al. found a prevalence of $36 \%$ when excluding the participants who had other (confounding) conditions but the prevalence was $64 \%$ when they were not excluded [23]. Therefore, the real prevalence of CAI in Koshino's and colleagues' study might be in a range of $36 \%$ to $64 \%$. In the current study the prevalence of CAI was $77 \%$. It can be estimated that the prevalence might be $39 \%$ if participants were excluded based on the exclusion criteria from the International Ankle Consortium. Therefore, the true prevalence of CAI in the current study might be located between 39 and $77 \%$. A standard method to identify the origin of perceived ankle instability is required to investigate the epidemiology of CAI; then participants with other conditions can be clearly categorized.

The high prevalence in the current study might be caused by the factors: preexisting perceived ankle instability, the period of the investigation and recovery conditions after ankle sprains. Preexisting perceived ankle instability might be a confounder when investigating the prevalence of CAI. In the current study, $30 \%$ of the participants without a history of ankle sprain showed perceived ankle instability (left ankle: 14/53 and right ankle 21/69). Therefore, there is a possibility that athletes with preexisting perceived ankle instability and a history of ankle sprain were categorized as CAI even though they regained the baseline level of perceived ankle stability after a severe ankle sprain. The current cross-sectional study cannot clarify if the perceived ankle instability is preexisting or caused by an ankle sprain.

The investigating period might be another explanation for the high prevalence of CAI. The current study was conducted one month before the start of the season. Most ankle injuries occur during the pre-season among collegiate basketball athletes [18]. In the pre-season, the training load intensity and duration are often higher than the in-season phase [39], leading to an increased risk of injury [40]. Recurrent ankle sprain is one of the signs of CAI. Therefore, a high rate of ankle injury in the preseason may contribute to a high prevalence of CAI. In 
addition, data to depict the prevalence of CAI in different seasons is scarce. The optimal method to investigate overuse injury or chronic pain (e.g. the symptoms of low back pain, patellar tendinopathy or shoulder pain) is to perform a prospective longitudinal study and to measure the symptoms at regular intervals, since the chronic pain may fluctuate among different training seasons [41]. In the case of CAI, the CAI-related symptoms have not been measured continuously in athletic populations. Therefore, it is not clear if the presence of perceived ankle instability, frequency of recurrent ankle sprain or giving way fluctuates with time or training seasons as the other overuse injuries.

The inadequate recovery or lacking rehabilitation after an ankle sprain might also contribute to the high prevalence of CAI. Doherty et al. showed that after an acute ankle sprain, $40 \%$ of the participants who did not seek rehabilitation developed CAI, and $60 \%$ who did became ankle sprain copers [42]. Nevertheless, the effect of seeking rehabilitation showed no statistical significance on ankle status [42]. In addition, only half of the athletes sought a healthcare provider after an ankle sprain [25, 43]. Koshino et al. found that there are no ankle sprain copers in the basketball population and only $4.3-5.3 \%$ in the whole surveyed cohort [23]. Absence from practices and competitions due to injuries sustained during preseason may affect participation in the in-season. Athletes might not recover properly after an ankle sprain and keep practicing with CAI. Secondary injuries could be developed with not properly healed tissue, such as sensoriperceptual or motor-behavioral impairments [7]. CAI affects the motor function of neuromuscular control and biomechanics on lower extremities, which might raise the risk of recurrent ankle sprains, cause post-traumatic osteoarthritis, increase the loading on the anterior cruciate ligament and further development of injuries [7]. Hence, managing CAI in the athletic population to prevent further unwanted injuries are essential.

\section{The prevalence of CAI and gender difference}

The current study found that gender influences the prevalence of CAI. Female athletes had a higher prevalence of CAI than men at the collegiate level. This is consistent with previous work [25]. In contrast, a survey of a military cohort showed that men had a 2.33 times greater incidence of mild CAI than women [44]. The gender difference in the incidence of ankle sprains is also inconsistent. Two studies showed no gender difference between athletes in high schools and between the WNBA and NBA $[15,21]$. One study found that male athletes in high school had a higher incidence of ankle injury than females [18].
The factors causing the differences in ankle injury rates between genders could be different anatomical structural, joint laxity and menstrual cycles [28, 29, 45-47]. Regarding anatomical structure, female collegiate athletes with an increased tibial varum and calcaneal eversion range of motion showed a greater risk of ankle sprain [48]. In the respect of joint laxity, women had a greater ligamentous laxity of the lateral ankle than men [28]. Regarding hormone fluctuation, women in the ovulating phase of menstrual cycles showed less postural stability than in the follicular phase [29, 46, 47]. Longitudinal studies are suggested to assess (1) the relation between a higher prevalence of CAI in women, (2) the underlying mechanism and (3) a specified prevention program for this population [41].

\section{The prevalence of CAI and different competitive levels}

The current study found that the athlete's competitive level did not relate to the prevalence of CAI. The relation between competitive level and ankle injury rate is not clear [20]. Two previous studies showed that athletes competing at a higher competitive level showed a lower prevalence of CAI $[25,38]$. This may relate to more advanced skills and injury prevention measures applied to higher-level athletes [20,49]. However, another study found that the rate of ankle sprains is higher among higher-level athletes than lower level [19]. Athletes at higher competitive levels may create more force when playing and this could result in a higher injury rate [30, 50].

The potential explanation for the inconsistent findings might be that athletes attend highly specialized training from a young age in Taiwan which is a risk factor for serious overuse injury [51]. Access to healthcare for young athletes was not common 10 years ago in Taiwan, which may lead to the development of CAI. Today $60 \%$ of the top ten high school basketball teams employ athletic trainers who provide injury care. The previously existing overuse injuries may last until they are at a higher level and cause the current result: a high prevalence of CAI.

\section{The prevalence of CAI and the different basketball positions}

The current study found that the different positions showed no difference in the prevalence of CAI. To the best of the authors' knowledge, no study has investigated the prevalence of CAI in different positions within basketball athletes. Regarding the relation of ankle injuries and positions, the outcome is inconsistent with previous works [18, 32, 34]. Previous studies found that athletes in the center and guard positions sustain the most ankle injuries. [18, 32, 34]. The center commonly has a size advantage for this position and needs to jump 
frequently for rebounds causing contact with other players and are therefore prone to suffer more injuries [34]. A guard in basketball sustains high physiological stress due to repetitive direction changes and may cause neuromuscular fatigue increasing the injury rate [18]. However, the current study and a previous study showed no difference between the different positions [32]. This might be due to the players' role being shared (e.g. guard position filling in for the forward position) and basic basketball movements. Although there are different basketball positions, the role of each athlete sometimes is not that distinct in Taiwan. Some athletes may play center and power forward at the same time and some play small forward and shooting guard at the same time. This may make the characteristics of the injury less distinguished. Besides, athletes in all positions perform the basic basketball movements including jumping, cuttings, rapid stop and sudden directional changes, which make an athlete prone to ankle sprains.

\section{Study limitations}

There were some limitations to the study. Firstly, the current study is a cross-sectional design that portrays the prevalence of CAI among Taiwanese basketball athletes in pre-season. The prevalence is not representative for the whole season. Factors that affect the prevalence of CAI cannot be determined from the current data. In addition, the mechanical instability has not been examined so the participants with solely ankle pathological laxity may not be shown in the results. Finally, due to limited study resources no physician was present to differentiate between CAI and ankle instability caused by other issues. This may lead to an overestimation of the prevalence of CAI in the current study.

\section{Conclusion}

An acute ankle sprain can cause the development of CAI, which can impact athletes negatively. In the current study, elite Taiwanese basketball athletes showed a higher prevalence of CAI than in previous studies. Female collegiate athletes have a higher prevalence of CAI than men. Competitive level and positions showed no difference in the prevalence of CAI. Prevention of chronic ankle instability should be a focus in basketball. Gender should be taken into consideration when applying the CAI prevention measures.

The recommendations for further studies investigating the prevalence of chronic ankle instability are: (1) prospective longitudinal study is recommended so the fluctuation of prevalence can be clearly depicted and the preexist perceived ankle instability will not confound the prevalence, (2) standard criteria for survey the prevalence of CAI should be developed, that can increase the precision of the prevalence, and (3) implementation of rehabilitation followed by ankle sprains should be reported.

\section{Abbreviations}

CAl: Chronic ankle instability; CAIT: The Cumberland Ankle Instability Tool; CAIT-TW: The Taiwan-Chinese version of the Cumberland Ankle Instability Tool; M: Mean; SD: Standard deviation; p: P-value.

\section{Supplementary Information}

The online version contains supplementary material available at https://doi. org/10.1186/s13102-022-00418-0.

Additional file 1. Demographic characteristics of participants.

Additional file 2. Demographical differences between genders in collegiate athletes $(n=255)$.

Additional file 3. Demographical differences between genders in the groups with and without chronic ankle instability ( $N=388)$.

Additional file 4. Demographical differences between genders in semiprofessional athletes $(n=133)$.

\section{Acknowledgements}

We acknowledge coaches, managers, and athletic trainers in the basketball teams who helped assist and manage the athletes who participated in this study. We are also grateful to all the participants attending this study. We are thankful to Henry Robert Mumm, Sanne Houtenbos and Niklas Pragsten who assisted with the proofreading.

\section{Authors' contributions}

CIL conceptualized the research idea, analyzed data, applied for funding, wrote the manuscript, obtained the resources, investigated, and administrated the project. FM reviewed the manuscript and supervised the project. PMW assisted funding acquisition, reviewed the manuscript, and supervised the project. All authors read and approved the final manuscript.

\section{Funding}

Open Access funding enabled and organized by Projekt DEAL. Funded by the German Research Foundation (Deutsche Forschungsgemeinschaft, DFG) - project number 491466077. This study was granted by the 2017 Studying Abroad Scholarship from the Taiwan Ministry of Education.

Availability of data and materials

The datasets used and/or analyzed during the current study are available from the corresponding author on reasonable request.

\section{Declarations}

Ethics approval and consent to participate

All participants read and signed the informed consent document before participating in the study. This study performed in accordance with the Declaration of Helsinki and was approved by the ethical committee at the University of Potsdam (Number: 25/2018). Study was conducted in October of 2018.

\section{Consent for publication}

Not applicable.

\section{Competing interests}

The authors declare that they have no competing interests.

\section{Author details}

${ }^{1}$ Medical Sociology and Psychobiology, Department of Physical Activity and Health, University of Potsdam, Am Neuen Palais 10, 14469 Potsdam, Germany. ${ }^{2}$ University Outpatient Clinic, Centre of Sports Medicine, University of Potsdam, Am Neuen Palais 10, 14469 Potsdam, Germany. ${ }^{3}$ Faculty 
of Health Sciences Brandenburg [Joint Faculty of the University of Potsdam, the Brandenburg Medical School Theodor Fontane and the Brandenburg University of Technology Cottbus - Senftenberg], Potsdam, Germany.

Received: 9 June 2021 Accepted: 1 February 2022 Published online: 18 February 2022

\section{References}

1. Doherty C, Delahunt E, Caulfield B, Hertel J, Ryan J, Bleakley C. The incidence and prevalence of ankle sprain injury: a systematic review and meta-analysis of prospective epidemiological studies. Sports Med. 2014;44(1):123-40. https://doi.org/10.1007/s40279-013-0102-5.

2. Anandacoomarasamy A, Barnsley L. Long term outcomes of inversion ankle injuries. Br J Sports Med. 2005;39(3):e14. https://doi.org/10.1136/ bjsm.2004.011676.

3. Gribble PA, Delahunt E, Bleakley C, Caulfield B, Docherty C, Fourchet $F$, et al. Selection criteria for patients with chronic ankle instability in controlled research: a position statement of the International Ankle Consortium. Brit J Sport Med. 2014. https://doi.org/10.1136/bjspo rts-2013-093175.

4. Gribble PA, Bleakley CM, Caulfield BM, Docherty CL, Fourchet F, Fong DTP, et al. Evidence review for the 2016 International Ankle Consortium consensus statement on the prevalence, impact and long-term consequences of lateral ankle sprains. Brit J Sports Med. 2016;50(24):1496. https://doi.org/10.1136/bjsports-2016-096189.

5. Hiller CE, Kilbreath SL, Refshauge KM. Chronic ankle instability: evolution of the model. J Athl Train. 2011;46(2):133-41. https://doi.org/10.4085/ 1062-6050-46.2.133

6. van Mechelen W, Hlobil H, Kemper HCG. Incidence, severity, aetiology and prevention of sports injuries. Sports Med. 1992;14(2):82-99. https:// doi.org/10.2165/00007256-199214020-00002.

7. Hertel J, Corbett RO. An updated model of chronic ankle instability. J Athl Train. 2019:54(6):572-88. https://doi.org/10.4085/1062-6050-344-18.

8. Bielska IA, Wang X, Lee R, Johnson AP. The health economics of ankle and foot sprains and fractures: a systematic review of English-language published papers. Part 2: the direct and indirect costs of injury. The Foot. 2019;39:115-21. https://doi.org/10.1016/j.foot.2017.07.003.

9. Oztekin HH, Boya H, Ozcan O, Zeren B, Pinar P. Foot and ankle injuries and time lost from play in professional soccer players. Foot. 2009;19(1):22-8. https://doi.org/10.1016/j.foot.2008.07.003.

10. Zuckerman SL, Wegner AM, Roos KG, Djoko A, Dompier TP, Kerr ZY. Injuries sustained in National Collegiate Athletic Association men's and women's basketball, 2009/2010-2014/2015. Brit J Sport Med. 2018;52(4):261-8. https://doi.org/10.1136/bjsports-2016-096005.

11. Palmer-Green D, Fuller C, Jaques R, Hunter G. The Injury/IIness Performance Project (IIPP): a novel epidemiological approach for recording the consequences of sports injuries and illnesses. J Sports Med. 2013:2013:523974. https://doi.org/10.1155/2013/523974.

12. Roos KG, Kerr ZY, Mauntel TC, Djoko A, Dompier TP, Wikstrom EA. The epidemiology of lateral ligament complex ankle sprains in National Collegiate Athletic Association Sports. Am J Sports Med. 2016:45(1):201-9. https://doi.org/10.1177/0363546516660980.

13. Morris SN, Chandran A, Lempke LB, Boltz AJ, Robison HJ, Collins CL. Epidemiology of Injuries in National Collegiate Athletic Association Men's Basketball: 2014-2015 through 2018-2019. J Athl Train. 2021;56(7):681-7. https://doi.org/10.4085/1062-6050-436-20.

14. Lempke LB, Chandran A, Boltz AJ, Robison HJ, Collins CL, Morris SN. Epidemiology of Injuries in National Collegiate Athletic Association Women's Basketball: 2014-2015 through 2018-2019. J Athl Train. 2021;56(7):67480. https://doi.org/10.4085/1062-6050-466-20.

15. Deitch JR, Starkey C, Walters SL, Moseley JB. Injury risk in professional basketball players - a comparison of Women's National Basketball Association and National Basketball Association athletes. Am J Sport Med. 2006;34(7):1077-83. https://doi.org/10.1177/0363546505285383.

16. Rodas G, Bove T, Caparros T, Langohr K, Medina D, Hamilton B, et al. Ankle sprain versus muscle strain injury in professional Men's Basketball: a 9-year prospective follow-up study. Orthopaed J Sports Med. 2019. https://doi.org/10.1177/2325967119849035.
17. Baker H, Rizzi A, Athiviraham A. Injury in the Women's National Basketball Association (WNBA) from 2015 to 2019. Arthrosc Sports Med Rehabil. 2020;2(3):e213-7. https://doi.org/10.1016/j.asmr.2020.02.003.

18. Tummala SV, Hartigan DE, Makovicka JL, Patel KA, Chhabra A. 10-year epidemiology of ankle injuries in men's and women's collegiate basketball. Orthopaed J Sports Med. 2018;6(11):66. https://doi.org/10.1177/ 2325967118805400

19. Clifton DR, Hertel J, Onate JA, Currie DW, Pierpoint LA, Wasserman $E B$, et al. The first decade of web-based sports injury surveillance: descriptive epidemiology of injuries in US High School Girls' Basketball (2005-2006 through 2013-2014) and National Collegiate Athletic Association Women's Basketball (2004-2005 Through 2013-2014). J Athl Train. 2018;53(11):1037-48. https://doi.org/10.4085/1062-6050-150-17.

20. Clifton DR, Onate JA, Hertel J, Pierpoint LA, Currie DW, Wasserman $E B$, et al. The first decade of web-based sports injury surveillance: descriptive epidemiology of injuries in US High School Boys' Basketball (2005-2006 through 2013-2014) and National Collegiate Athletic Association Men's Basketball (2004-2005 through 2013-2014). J Athl Train. 2018;53(11):1025-36. https://doi.org/10.4085/1062-6050-148-17.

21. Pasanen K, Ekola T, Vasankari T, Kannus P, Heinonen A, Kujala UM, et al. High ankle injury rate in adolescent basketball: a 3-year prospective follow-up study. Scand J Med Sci Sports. 2017;27(6):643-9. https://doi. org/10.1111/sms.12818.

22. Attenborough AS, Hiller CE, Smith RM, Stuelcken M, Greene A, Sinclair PJ. Chronic ankle instability in sporting populations. Sports Med. 2014;44(11):1545-56. https://doi.org/10.1007/s40279-014-0218-2.

23. Koshino Y, Samukawa M, Murata H, Osuka S, Kasahara S, Yamanaka M, et al. Prevalence and characteristics of chronic ankle instability and copers identified by the criteria for research and clinical practice in collegiate athletes. Phys Ther Sport. 2020;45:23-9. https://doi.org/10. 1016/j.ptsp.2020.05.014.

24. Kobayashi T, Takabayashi T, Kudo S, Edama M. The prevalence of chronic ankle instability and its relationship to foot arch characteristics in female collegiate athletes. Phys Ther Sport. 2020;46:162-8. https:// doi.org/10.1016/j.ptsp.2020.09.002.

25. Tanen L, Docherty CL, Van Der Pol B, Simon J, Schrader J. Prevalence of chronic ankle instability in high school and division I athletes. Foot Ankle Spec. 2014;7(1):37-44. https://doi.org/10.1177/1938640013 509670.

26. Lin C-I, Houtenbos S, Lu Y-H, Mayer F, Wippert P-M. The epidemiology of chronic ankle instability with perceived ankle instability - a systematic review. J Foot Ankle Res. 2021;14(1):41. https://doi.org/10.1186/ s13047-021-00480-w.

27. Borowski LA, Yard EE, Fields SK, Comstock RD. The epidemiology of US High School Basketball injuries, 2005-2007. Am J Sports Med. 2008;36(12):2328-35. https://doi.org/10.1177/0363546508322893.

28. Wilkerson RD, Mason MA. Differences in men's and women's mean ankle ligamentous laxity. lowa Orthop J. 2000;20:46-8.

29. Khowailed IA, Lee H. Neuromuscular control of ankle-stabilizing muscles-specific effects of sex and menstrual cycle. Int J Sports Med. 2021:42(03):270-6. https://doi.org/10.1055/a-1236-3654.

30. Fousekis $K$, Tsepis $E$, Vagenas $G$. Intrinsic risk factors of noncontact ankle sprains in soccer: a prospective study on 100 professional players. Am J Sports Med. 2012;40(8):1842-50. https://doi.org/10.1177/ 0363546512449602.

31. Clifton DR, Koldenhoven RM, Hertel J, Onate JA, Dompier TP, Kerr ZY. Epidemiological patterns of ankle sprains in youth, high school, and college football. Am J Sports Med. 2016;45(2):417-25. https://doi.org/ $10.1177 / 0363546516667914$.

32. McKay GD, Goldie PA, Payne WR, Oakes BW. Ankle injuries in basketball: injury rate and risk factors. Br J Sports Med. 2001;35(2):103-8. https:// doi.org/10.1136/bjsm.35.2.103.

33. Ben Abdelkrim N, Chaouachi A, Chamari K, Chtara M, Castagna C. Positional role and competitive-level differences in Elite-Level Men's Basketball players. J Strength Condition Res. 2010;24(5):66. https://doi. org/10.1519/JSC.0b013e3181cf7510.

34. Vanderlei FM, Bastos FN, de Lemes IR, Vanderlei LCM, Júnior JN, Pastre CM. Sports injuries among adolescent basketball players according to position on the court. Int Arch Med. 2013;6(1):5. https://doi.org/10. $1186 / 1755-7682-6-5$ 
35. Pojskić H, Šeparović V, Užičanin E, Muratović M, Mačković S. Positional role differences in the aerobic and anaerobic power of Elite Basketball Players. J Hum Kinet. 2015;49:219-27. https://doi.org/10.1515/hukin-2015-0124.

36. Hootman JM, Dick R, Agel J. Epidemiology of collegiate injuries for 15 sports: summary and recommendations for injury prevention initiatives. J Athl Train. 2007;42(2):311-9.

37. Lin C-I, Mayer F, Wippert P-M. Cross-cultural adaptation, reliability, and validation of the Taiwan-Chinese version of Cumberland Ankle Instability Tool. Disabil Rehabil. 2020. https://doi.org/10.1080/09638288.2020.17749 28.

38. Attenborough AS, Sinclair PJ, Sharp T, Greene A, Stuelcken M, Smith RM, et al. A snapshot of chronic ankle instability in a cohort of netball players. J Sci Med Sport. 2016;19(5):379-83. https://doi.org/10.1016/j.jsams.2015. 04.010 .

39. Aoki MS, Ronda LT, Marcelino PR, Drago G, Carling C, Bradley PS, et al. Monitoring training loads in professional basketball players engaged in a periodized training program. J Strength Condit Res. 2017;31 (2):666. https://doi.org/10.1519/JSC.00000000000001507.

40. Gabbett TJ. Influence of training and match intensity on injuries in rugby league. J Sport Sci. 2004;22(5):409-17. https://doi.org/10.1080/02640 410310001641638.

41. Bahr R. No injuries, but plenty of pain? On the methodology for recording overuse symptoms in sports. Br J Sports Med. 2009;43(13):966. https:// doi.org/10.1136/bjsm.2009.066936.

42. Doherty C, Bleakley C, Hertel J, Caulfield B, Ryan J, Delahunt E. Recovery from a first-time lateral ankle sprain and the predictors of chronic ankle instability: a prospective cohort analysis. Am J Sport Med. 2016;44(4):9951003. https://doi.org/10.1177/0363546516628870.

43. Kellmann M. Preventing overtraining in athletes in high-intensity sports and stress/recovery monitoring. Scand J Med Sci Spor. 2010;20(s2):95102. https://doi.org/10.1111/j.1600-0838.2010.01192.x.

44. Hershkovich O, Tenenbaum S, Gordon B, Bruck N, Thein R, Derazne E, et al. A large-scale study on epidemiology and risk factors for chronic ankle instability in young adults. J Foot Ankle Surg. 2015;54(2):183-7. https:// doi.org/10.1053/j.jfas.2014.06.001.

45. Beynnon BD, Vacek PM, Murphy D, Alosa D, Paller D. First-time inversion ankle ligament trauma: the effects of sex, level of competition, and sport on the incidence of injury. Am J Sports Med. 2005;33(10):1485-91. https://doi.org/10.1177/0363546505275490.

46. Lee H, Yim J. Increased postural sway and changes in the neuromuscular activities of the ankle stabilizing muscles at ovulation in healthy young women. Tohoku J Exp Med. 2016;240(4):287-94. https://doi.org/10.1620/ tjem.240.287.

47. Yim J, Petrofsky J, Lee H. Correlation between mechanical properties of the ankle muscles and postural sway during the menstrual cycle. Tohoku J Exp Med. 2018;244(3):201-7. https://doi.org/10.1620/tjem.244.201.

48. Beynnon BD, Renstrom PA, Alosa DM, Baumhauer JF, Vacek PM. Ankle ligament injury risk factors: a prospective study of college athletes. J Orthop Res. 2001;19(2):213-20. https://doi.org/10.1016/S0736-0266(00) 90004-4.

49. Yeung MS, Chan KM, So CH, Yuan WY. An epidemiological survey on ankle sprain. Br J Sports Med. 1994;28(2):112-6. https://doi.org/10.1136/bjsm. 28.2.112.

50. Tyler TF, McHugh MP, Mirabella MR, Mullaney MJ, Nicholas SJ. Risk factors for noncontact ankle sprains in high school football players: the role of previous ankle sprains and body mass index. Am J Sports Med. 2006;34(3):471-5. https://doi.org/10.1177/0363546505280429.

51. Jayanthi NA, LaBella CR, Fischer D, Pasulka J, Dugas LR. Sports-specialized intensive training and the risk of injury in young athletes: a clinical casecontrol study. Am J Sports Med. 2015;43(4):794-801. https://doi.org/10. 1177/0363546514567298

\section{Publisher's Note}

Springer Nature remains neutral with regard to jurisdictional claims in published maps and institutional affiliations.

Ready to submit your research? Choose BMC and benefit from:

- fast, convenient online submission

- thorough peer review by experienced researchers in your field

- rapid publication on acceptance

- support for research data, including large and complex data types

- gold Open Access which fosters wider collaboration and increased citations

- maximum visibility for your research: over $100 \mathrm{M}$ website views per year

At BMC, research is always in progress.

Learn more biomedcentral.com/submissions 